DOI: https://doi.org/10.14232/actahisp.2020.25.67-86

\title{
LAS RESTRICCIONES EN EL USO DE LOS PREDICADOS ESTATIVOS EN LA LENGUA ESPAÑOLA
}

\author{
CSILla NÉMETHNÉ ERDÉLYI
}

Universidad Eötvös Loránd, Hungría

\begin{abstract}
Resumen: El objetivo de este artículo es analizar el comportamiento de los predicados estativos de la lengua española, en particular su compatibilidad con algunos adverbios, algunas perífrasis verbales y el modo imperativo. Para realizar esto, es necesario distinguir los verbos y predicados de estado de los verbos dinámicos y hacer una clasificación de las situaciones que describen un estado. En conclusión voy a determinar diferentes grupos entre los predicados estativos dependiendo de los diferentes estados descritos.
\end{abstract}

Palabras clave: predicados estativos, perífrasis verbales, adverbios de modo, modo imperativo.

Abstract: The aim of this article is to analyse the behaviour of stative predicates in Spanish, particularly their compatibility with some adverbs, some verbal periphrasis and the imperative mode. In order to do this it is necessary to distinguish the stative verbs and predicates from the dynamic verbs and distinguish the stable situations from each other. I will create some groups between the stative predicates to see the differences between the states. In conclusion I will determine different groups of the stative predicates in dependence from the different states described in the article.

Keywords: Stative Predicates, Verbal Periphrases, Modal Adverbs, Imperative Mode.

\section{Introducción}

En este estudio voy a presentar algunas restricciones referentes al uso de los predicados estativos para realizar una clasificación que refleje las características aspectuales y de modo de acción de los predicados de estado. Estos predicados se llaman predicados de estado o predicados estativos porque las situaciones que describen son estables, es decir se mantienen durante un cierto período de tiempo (Smith, 1997: 32). Sin embargo, parece que no son estables de la misma manera: Soy alto expresa un estado que no puede cambiar, pero Tengo 10 libros sobre matemáticas describe una situación que puede terminar. Ambos son estados, pero son diferentes. A pesar de las diferencias, muchos de los predicados estativos comparten algunas características entre sí, como la incompatibilidad con el modo imperativo y con los adverbios de modo. Sin embargo, a veces es posible combinar algunos predicados de estado con este modo y estos adverbios.

Primero voy a presentar las características generales de los predicados estativos basándome en The parameter of aspect de Carlota Smith. Luego, voy a describir la caracterización de estos predicados en la lingüística española para ver si hay diferencias entre las teorías. Después voy a analizar la compatibilidad de los predicados estativos 
Las restricciones en el uso de los predicados estativos en la lengua española

con el modo imperativo, con algunos adverbios de modo, y con algunas perífrasis verbales. Voy a utilizar ejemplos que han sido revisados por hablantes nativos.

\section{Los predicados estativos}

\subsection{Características generales}

En su libro The parameter of aspect (1997) Carlota Smith describe un sistema de aspecto de dos niveles: uno es el aspecto de punto de vista y el otro es el aspecto situacional (Smith, 1997: 3). El tema de los predicados estativos forma parte del aspecto situacional, mientras que el aspecto de punto de vista pertenece al tema del aspecto gramatical. En el capítulo del aspecto situacional Smith describe los diferentes tipos de situaciones a base de tres características básicas: la dinamicidad, la duratividad y la telicidad. Así, distingue cinco tipos de situación: los estados (Soy búngara), las actividades (Pedro sonríe mucho), las realizaciones (Ayer aprendi estas palabras), los eventos momentáneos (Después de esperar algunos minutos, llamé a la puerta) y los resultados (Estaba haciendo las maletas y encontré mi pasaporte desaparecido). Los estados difieren de los otros tipos en la dinamicidad: los estados son situaciones estáticas, mientras que las demás situaciones son dinámicas. Estos cuatro tipos pueden ser durativos, como las actividades y las realizaciones, o instantáneos, como los eventos momentáneos y los resultados. La tercera característica, la telicidad se refiere al término del evento: si el evento tiene un final determinado en el que se cumple la acción, es télico, pero si no lo tiene, es decir, si el evento no termina con un cambio de estado, es atélico. Las actividades y los eventos momentáneos son atélicos y las realizaciones y los resultados son télicos (Smith, 1997: 20).

Como ya he mencionado, los predicados estativos expresan situaciones estables. Estas situaciones siempre son durativas y atélicas. El punto inicial y el punto final nunca están incluidos en la situación. Existen algunos estados típicos como las situaciones que expresan aspecto físico (ser alto), un estado físico o mental (estar cansado, estar triste), posesión (tener una casa), creencia (creer en fantasmas), nacionalidad (ser inglés) o estancia (estar en Londres) (Smith, 1997: 32). Los estados siempre son durativos, como se puede ver en los ejemplos anteriores, pero la duración de las situaciones puede ser corta (A las seis de la mañana el nivel de agua fue 1,5m y estaba aumentando) o larga (Mi amiga tiene dos casas y un piso en esta ciudad). El punto común en estas situaciones es la estabilidad, que no depende de la duración. El estado expresado por el predicado debe mantenerse durante el período de tiempo señalado en la oración. Como en la oración: A las seis de la mañana el nivel de agua fue $1,5 m$ y estaba aumentando la duración del estado es corta, pero la situación se mantiene durante este intervalo corto, por esta razón es una situación estable. La estabilidad conlleva que la situación no alcanza ningún punto de culminación o un cambio. Si el estado cambia, ya no podemos hablar sobre un estado, sino que se trata de otro tipo de situación, como en el siguiente ejemplo: Ana estaba enferma y tuvo que guardar cama por días. Después de una semana se curó y estaba sana. Los dos estados de la oración, estar enferma y estar 
sana son situaciones estables. El estado mismo cambia, pero este cambio está expresado por otro predicado: curarse, que es una realización.

\subsection{Reglas de uso de los predicados estativos}

Las características de los predicados de estado, como la estatividad, la duratividad y la atelicidad causan que estos predicados no pueden ser utilizados con cualquier modo y con cualquier tipo de adverbio. En este apartado voy a presentar las restricciones enumeradas por Smith (1997) referentes al uso de los predicados de estado.

Según Smith, los predicados estativos, como son estáticos, no son compatibles con el modo imperativo y con las construcciones de predicados que expresan mandato, voluntad o petición (ask, command etc.), como vemos en las oraciones:

$1 \mathrm{a},{ }^{*}$ Know English!

b, $*$ I ask you to know English.

Esta incompatibilidad se debe a la estatividad de los predicados de estado, puesto que el modo imperativo y las construcciones mencionadas requieren situaciones dinámicas. Sin embargo, la dinamicidad está en relación con la agentividad. Un evento dinámico, generalmente, tiene agente, pero las situaciones estáticas no suelen tenerlo (V. apartado 3). Esta característica da como resultado que los predicados de estado no pueden ser utilizados con la mayoría de los adverbios de modo.

$2 *$ He carefully knows Spanish.

Los adverbios de modo requieren situaciones que tienen agente. Sin embargo, como estos predicados no son dinámicos sino estáticos, no pueden tener agente (Smith, 1997: 40).

Los predicados de estado son compatibles con los adverbios que expresan duración (He was ill during last week) y con los adverbios momentáneos (He was asleep at midnight). Sin embargo, no pueden aparecer con adverbios que expresan duración indirectamente, como slowly: * She was slowly ill. Estos tipos de adverbios requieren predicados que expresan algún tipo de actividad (Smith, 1997: 47).

\section{La relación entre estatividad y agentividad}

Como hemos visto en el apartado anterior, muchas veces la compatibilidad de algún modo o adverbio con los predicados estativos depende de si la situación tiene agente o no. Smith afirma que los estados no pueden tener agente, es decir un sujeto que controla la situación (Smith, 1997: 40). Según mi opinión, solo algunos tipos de los predicados estativos funcionan siempre sin agente, como los que expresan propiedades de aspecto físico, nacionalidad y capacidad. En el caso de estos estados el sujeto no controla la situación.

3 a, Peter is tall.

b, Peter is English.

c, Peter can drive.

Acta Hispanica 25: 67-86, 2020, ISSN 1416-7263, e-ISSN 2676-9719 | 69 
Las restricciones en el uso de los predicados estativos en la lengua española

En (3a) y (3b) la propiedad y la nacionalidad no es el resultado de la actividad de Peter. En (3c) la capacidad existe por la actividad de Peter, por el aprendizaje, pero el sujeto ya no puede controlar la situación. En el caso de estos estados no podemos utilizar la perífrasis to stop doing something:

4 a, *Peter stops being tall.

b, *Peter stops being English.

c, *Peter stops being able to drive.

Los demás estados, como los que se refieren a estados físicos o mentales, los que expresan posesión, estancia, creencia, pueden tener "agente", o mejor dicho, hasta cierto punto, pueden ser controlados por un sujeto. En este caso, es posible utilizarlos con la perífrasis to stop doing something.

5 a, Peter is angry.

b, Peter stopped being angry.

c, Peter has two dogs.

d, Peter stopped having two dogs.

e, Peter is in New York.

f, Peter stopped being in New York.

$\mathrm{g}$, Peter believes in ghosts.

$\mathrm{h}$, Peter stopped believing in ghosts.

Como en (5a-h) el sujeto controla la situación, supuestamente, en estos casos los predicados estativos son compatibles tanto con el modo imperativo como con las construcciones de mandato:
6 a, Be angry!
b, I ask you to have two dogs.
c, I ask you to be in New York.
$\mathrm{d}$, Believe in ghosts!

En (6a-d) aparecen oraciones correctas con predicados estativos utilizados en modo imperativo o con un predicado de petición, así que podemos ver que la presencia del "agente" modifica la compatibilidad de los estados con estas construcciones.

\section{Los predicados de estado en la lengua española}

\subsection{Los tipos de predicados de estado}

Como en el caso de Smith, en la gramatografía de la lengua española también aparece el tema de los predicados (verbos) estativos dentro del tema del aspecto. En español también se puede distinguir el aspecto flexivo y el aspecto léxico. El primero informa sobre el modo del curso de un evento. El aspecto flexivo está expresado por morfemas gramaticales y puede ser perfectivo e imperfectivo ${ }^{1}$ (De Miguel, 1999: 2987). Esta

\footnotetext{
${ }^{1}$ De Miguel presenta el tema del aspecto desde el punto de vista de los verbos.
} 
categoría corresponde al aspecto de punto de vista de Smith. El aspecto léxico también expresa cómo ocurre el evento, sin embargo, esta información está proporcionada por los lexemas verbales (reconocer - evento semelfactivo), perífrasis verbales (ponerse a - evento semelfactivo), conjugación pronominal (Él se comió la tarta - evento delimitativo), a veces por los complementos del verbo (Pedro fuma un cigarrillo - evento delimitativo). Esta categoría corresponde al aspecto situacional de Smith. El tema de los predicados estativos pertenece al aspecto léxico en la lengua española también.

En español se pueden distinguir dos grandes grupos de situaciones: las situaciones estáticas y las situaciones dinámicas. Las situaciones estáticas de la lengua española tienen las mismas propiedades que ya he mencionado arriba a base de la obra de Smith (1997): se dan durante un cierto período de tiempo y no pueden expresar cambios (De Miguel, 1999: 3012). Dentro de las situaciones estáticas en la Gramática descriptiva de la lengua española (1999), Elena de Miguel establece ciertos tipos de estado: las propiedades inalienables del sujeto (ser inteligente) y estados que se mantienen solo bajo ciertas condiciones (saber, querer) ${ }^{2}$. Este segundo grupo contiene los verbos de posesión, los que expresan permanencia en un estado o situación (contener, residir), verbos que pueden expresar duración (seguir), los verbos pseudoatributivos (ser conocido como) y verbos que expresan emociones o sensaciones llamados verbos sentiendi (amar) (De Miguel, 1999: 3013). Estos tipos de predicados disponen de las características determinadas por Smith: son estáticos, durativos y atélicos. Las diferencias se encuentran en la duración: los predicados estativos que se refieren a propiedades inalienables del sujeto generalmente se mantienen durante más tiempo que los estados que indican, por ejemplo, posesión. Sin embargo, muchas veces podemos encontrar estados que, a pesar de que no expresan posesión, aparecen con el verbo tener como tener miedo, tener los ojos verdes etc. El verbo tener siempre expresa una relación general entre el sujeto y el complemento directo de la oración. Esta relación se interpreta generalmente como posesión, pero puede expresar la presencia de una sensación o sentimiento en el sujeto (tener miedo, tener hambre) o a veces se refiere a una característica del sujeto (tener los ojos verdes). Según mi opinión, los estados prototípicos son los que expresan propiedades inalienables y los que expresan nacionalidad. Voy a crear dos nuevos grupos: uno para los predicados que se refieren a un estado físico o mental no permanente (los adjetivos que expresan esto generalmente se utilizan con el verbo estar) y otro para los estados que expresan conocimiento. Según mi opinión, los estados que expresan duración, utilizados con el verbo seguir o continuar no forman un grupo aparte de los demás estados. Estos verbos utilizados en sí mismos expresan una actividad no una situación estática: Sigo a un fugitivo a la frontera mexicana. Continué mi camino sin mirar atrás. Estas situaciones son compatibles con el adverbio lentamente y con el modo imperativo también, por eso no pueden ser situaciones estáticas. En la siguiente tabla enumero los grupos de estados que voy a analizar más abajo.

\footnotetext{
2 Silvia Ramírez Gelbes presenta una distribución alternativa.
} 
Las restricciones en el uso de los predicados estativos en la lengua española

\begin{tabular}{|l|l|}
\hline Tipo de estado & Ejemplos \\
\hline propiedad inalienable del sujeto & ser alto, tener los ojos azules \\
\hline nacionalidad & ser híngaro \\
\hline conocimiento & saber, conocer \\
\hline estado físico o mental no permanente & estar cansado, estar alegre \\
\hline permanencia en un estado o situación & residir, permanecer \\
\hline posesión & tener libros \\
\hline verbos pseudoatributivos & ser conocido como, parecerse \\
\hline pensamientos, emociones, sensaciones & temer, amar \\
\hline
\end{tabular}

\subsection{Las restricciones en el uso de los predicados estativos}

En este apartado voy a analizar la compatibilidad de los predicados de estado con el modo imperativo, con las construcciones que expresan mandato o petición y con adverbios de modo. Como hemos visto, la compatibilidad de los predicados estativos en estas construcciones está en relación con la presencia de un "agente" en la oración. Después de analizar la influencia de la agentividad en el uso de los predicados estativos mencionados arriba, en la segunda parte de este apartado voy a analizar el uso de algunas perífrasis verbales con los predicados de estado.

En general, se afirma que los predicados de estado no pueden ser utilizados con el modo imperativo, dado que este modo requiere un evento que tiene "agente". Podemos ver en los siguientes ejemplos que en español ocurre lo mismo:

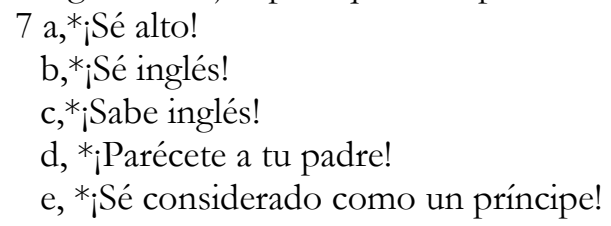

Sin embargo, resulta que los predicados que expresan conocimiento de algo o alguien, un estado físico o mental, permanencia en un estado o situación, los verbos de posesión y los verbos sentiendi pueden aparecer en modo imperativo:

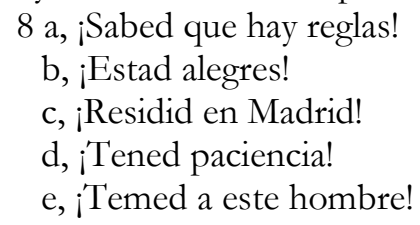

En el caso de los estados (8a-e) el sujeto es capaz de influir en la situación de alguna manera, por eso es posible utilizarlos en el modo imperativo. A veces algunas propiedades con el verbo ser también se expresan en imperativo: jSed honestos! pero en estos casos también el sujeto de las oraciones puede controlar la situación. Los verbos que expresan conocimiento a veces pueden aparecer en modo imperativo: jSabe la verdad!, ;Conoce esta ciudad!, pero en estos casos la oración se refiere a la adquisición del 
conocimiento, es decir ya no podemos hablar sobre un estado sino el evento tiene que ser interpretado como una realización. Tenemos que distinguir dos tipos de conocimientos: uno que se refiere al "saber hacer" (know-how) y otro que se refiere al conocimiento de alguna información o de alguna entidad (know-what/who/why). En el caso del primer grupo no es posible el uso con el modo imperativo, pero el segundo grupo de verbos puede ser utilizado con este modo, sin embargo, el tipo de situación será diferente.

$\mathrm{Si}$ analizamos estas construcciones en imperativo negativo vamos a recibir los mismos resultados. Podemos ver que los estados que expresan propiedades inalienables o nacionalidad generalmente no se utilizan en imperativo negativo tampoco:

9 a, ${ }^{*}$ No seas alto.

$\mathrm{b},{ }^{*}$ No seas inglés.

c, $*$ No sepas inglés.

d, $*$ No te parezcas a tu padre.

e, *No seas denominado como el Rey del fútbol.

Los demás tipos pueden aparecer en estas construcciones:

10 a, No sepas la verdad.

b, No estés cansado.

c, No permanezcas en la oscuridad.

d, No tengas planes nuevos.

e, No ames a esta mujer.

En el caso de (10a-e), la compatibilidad con el imperativo negativo está en relación con la presencia de un "agente". Los estados que expresan propiedades inalienables, la nacionalidad y el conocimiento son situaciones que no tienen agente, mientras que en el caso de los demás estados el sujeto tiene el control sobre la situación. En (10a) el tipo de situación no puede ser estado sino debe ser interpretado como realización.

En cuanto a los predicados que expresan mandato o petición, voy a analizar la compatibilidad de los estados con el verbo pedir:

$11 \mathrm{a},{ }^{*}$ Te pido que seas alto.

$\mathrm{b},{ }^{*}$ Te pido que seas inglés.

c, ${ }^{*}$ Te pido que sepas inglés.

d, *'Te pido que te parezcas a tu padre.

e, *Te pido que seas considerado como un príncipe.

$\mathrm{f}$, Te pido que sepas la verdad.

$\mathrm{g}$, Te pido que estés alegre.

$\mathrm{h}$, Te pido que residas en Madrid.

i, Te pido que tengas paciencia.

j, Te pido que me ames. 
Las restricciones en el uso de los predicados estativos en la lengua española

Podemos ver que, excepto los estados que expresan propiedades inalienables, nacionalidad o capacidad, los demás predicados estativos, (11f $\mathrm{f}-\mathrm{j})$ pueden aparecer en una construcción del verbo pedir y esto también se debe a la presencia de un "agente". En el caso de (11f) la situación puede ser interpretada solo como una realización.

En cuanto a los adverbios de modo, en la mayoría de los casos son incompatibles con los predicados estativos. Por ejemplo, el adverbio prudentemente no es compatible con ninguno de los estados:

12 a, $*$ Es prudentemente alto.

$\mathrm{b},{ }^{*}$ Es prudentemente inglés.

c, *Sabe prudentemente español.

$\mathrm{d},{ }^{*}$ Te pareces prudentemente a ella.

e, ${ }^{*}$ Eres prudentemente considerado como un príncipe.

f, *Está prudentemente alegre.

$\mathrm{g}$, Reside prudentemente en Madrid.

$\mathrm{h}$, *Tiene prudentemente paciencia.

i, *Sabe prudentemente la verdad.

j, *Pedro ama prudentemente a Ana.

En el caso de (12a-j) el adverbio modifica el predicado, por eso las oraciones no son aceptables. En cambio, si se trata de una construcción que tiene "agente", el adverbio puede modificarlo y de esta manera es posible el uso de adverbio de modo con un predicado estativo. En estos casos, se puede sustituir la construcción con la paráfrasis ser + atributo por parte de Sujeto (Kovacci, 1999: 751).

13 a, Pedro, prudentemente, reside en Madrid.

b, Es prudente por parte de Pedro residir en Madrid.

c, Pedro, prudentemente, tiene dos coches.

d, Es prudente por parte de Pedro tener dos coches.

e, Pedro, prudentemente, ama a Ana.

f, Es prudente por parte de Pedro amar a Ana.

En otros casos también es posible añadir un adverbio de modo a los predicados de estado:

14 a, Supe rápidamente lo que tenía que hacer.

b, Pedro conoce minuciosamente la cultura griega.

c, Ana quiere a su novio apasionadamente.

d, *Pedro conoce la cultura griega y lo hace minuciosamente.

e, *Ana quiere a su novio y lo hace apasionadamente.

En (14a), como ya hemos visto más arriba, el tipo de situación es una realización, por eso se puede añadir un adverbio de modo a la oración. Sin embargo, en el caso de (14b) y (14c) no se trata del uso prototípico del adverbio de modo, puesto que no podemos decir que Pedro lo hace minuciosamente o que Ana lo hace apasionadamente como vemos en $(14 \mathrm{~d})$ y $(14 \mathrm{e})$. Al contrario, en el caso de otro tipo de situación, por ejemplo una actividad, podemos modificar la oración de esta manera: 
15 a, Pedro estudia minuciosamente la cultura griega.

b, Pedro estudia la cultura griega y lo hace minuciosamente.

c, Pedro estudia apasionadamente la cultura griega.

d, Pedro estudia la cultura griega y lo hace apasionadamente.

La compatibilidad de algunos adverbios de modo con algunos de los estados se debe a que estos adverbios, combinando con un predicado estativo, no se interpretan como adverbio de modo, sino que son más bien adverbios de grado, mientras que en caso de una actividad el adverbio se refiere al modo del evento (Katz, 2003: 468).

\subsubsection{E1 uso de algunas perífrasis verbales con los predicados estativos}

Como hemos visto en la parte anterior, el uso del modo imperativo y del imperativo negativo con los predicados estativos depende de la presencia de un "agente" y el uso de algunos adverbios de modo con algunos estados puede cambiar la interpretación del adverbio. En esta parte voy a analizar la compatibilidad de algunas perífrasis verbales con los predicados estativos. Las perífrasis verbales modales siempre son compatibles con los predicados estativos, como muestra (16a-i).

$16 \mathrm{a}$, Tiene que ser inteligente.

b, Debe de ser inglés.

c, Debe de estar cansado.

d, Puede tener muchos libros.

e, Debe parecerse a su padre.

f, Debe ser considerado como un príncipe.

g, Debe de residir en Madrid.

h, Puede saber español.

i, Puede conocer esta ciudad.

j, Debes amar a tu padre.

A pesar de que las perífrasis modales pueden ser utilizadas con los diferentes tipos de estados, no todas las interpretaciones son posibles. Como en algunos casos falta el “agente", en (16a) y (16e) no es posible la interpretación deóntica de las oraciones, solo una interpretación epistémica (Laca, 2005: 3). En dos casos las oraciones pueden tener interpretación deóntica, no solo epistémica: en (16j), puesto que esta oración puede expresar una obligación del sujeto y en (16f), por la presencia de un "agente". En (16b), (16c) y (16g) solo es posible la interpretación epistémica puesto que la perífrasis deber de + infinitivo solo permite esta interpretación. En el caso de (16d), (16h) y (16i) se puede interpretar las oraciones de manera epistémica y también deóntica. La interpretación deóntica es posible si las frases expresan permiso. Si la construcción modal permite ambas interpretaciones, en el caso de los predicados de estado típicos solo es posible una interpretación epistémica: 
Las restricciones en el uso de los predicados estativos en la lengua española

17 a, Tienes que ser inglés.

$\mathrm{b}$, Tienes que estar cansado.

c, Debe tener muchos libros.

d, Tiene que residir en Madrid.

e, Debes saber español.

$\mathrm{f}$, Tienes que conocer la ciudad.

En (17a-f) las oraciones expresan la opinión del hablante, así que son epistémicas. En (17d) y en (17f) es posible una interpretación deóntica también, pero en ambos casos tenemos que interpretar las situaciones como una realización y no como un estado.

Las perífrasis verbales aspectuales pueden modificar el aspecto de una construcción. Pertenecen a este grupo las perífrasis llevar + gerundio y soler + infinitivo. Llevar + gerundio tiene un significado inclusivo, es decir la situación ha empezado antes del tiempo de referencia, dura en ello y continuará después del punto de referencia (Lleva 10 años trabajando aqui). Soler + infinitivo expresa un hábito (Suelo comprar las frutas en este mercado), tiene un significado iterativo. Los siguientes ejemplos muestran que algunos de los estados no pueden aparecer en la construcción llevar + gerundio:

18 a, *Lleva años siendo inteligente

b, *Lleva meses siendo francés

c, *Lleva horas sabiendo inglés

d, *Lleva meses pareciéndose a su padre

Como la perífrasis llevar + gerundio expresa el aspecto inclusivo, es decir que el evento está en proceso desde hace algún tiempo y va a continuar después del tiempo de referencia, no tiene sentido utilizar la perífrasis con los predicados estativos, puesto que estos estados no procesan en el tiempo sino se mantienen durante un cierto período de tiempo. Los demás estados aceptan esta perífrasis:

19 a, Lleva horas estando cansado.

b, Lleva años teniendo este coche.

c, Lleva años siendo considerado como un esclavo.

d, Lleva meses residiendo en esta ciudad.

e, Lleva años conociendo su mejor amigo.

f, Lleva meses amando a Pilar.

La diferencia entre los predicados de estado de (18a-d) y de (19a-f) es que estos últimos pueden ser interpretados como estados no permanentes por eso se puede destacar el tiempo durante el que se mantiene el estado. En cuanto a la perífrasis soler + infinitivo, que expresa el aspecto iterativo, resulta que el uso es diferente al de la construcción anterior:

20 a, *Pedro suele ser alto.

b, Los jugadores de baloncesto suelen ser altos.

c, $*$ Pedro suele ser inglés.

d, Los empleados de esta empresa suelen ser ingleses.

76 | Acta Hispanica 25: 67-86, 2020, ISSN 1416-7263, e-ISSN 2676-9719 
e, *Pedro suele saber español.

$\mathrm{f}$, Los que viven en Cuba suelen saber español.

$\mathrm{g}$, Suele estar cansado.

h, Suele residir en Madrid cuando está en España.

i, Suele ser considerado como un esclavo.

$\mathrm{j}$, Suele tener dos coches.

$\mathrm{k}$, Suele conocer los mejores restaurantes.

1 , Suele temer a los perros.

En el caso de esta perífrasis hay distintos factores por los que es compatible con los predicados estativos. En (20g) la perífrasis es compatible con el estado porque cansado significa un estado pasajero, así que es posible que se repita, por eso puede ser expresado como una costumbre. Las oraciones de (20h-l) también pueden ser interpretadas como una costumbre o como una situación general. (20a), (20c) y (20e) muestran que los predicados que expresan propiedad inalienable, nacionalidad $\mathrm{o}$ conocimiento de tipo saber hacer no pueden aparecer con la perífrasis soler + infinitivo. Sin embargo, en (20b), (20d) y (20f) estos tipos de estados aparecen en esta construcción. La diferencia es que en (20b), (20d) y (20f) la perífrasis no se refiere a un estado individual porque no se puede decir que *Este jugador de baloncesto suele ser alto, sino expresa una situación general. En este caso, es posible sustituir la perífrasis con el adverbio generalmente más el predicado estativo:

21 a, Los jugadores de baloncesto generalmente son altos.

b, Los empleados de esta empresa generalmente son ingleses.

c, Los que viven en Cuba generalmente saben español.

d, *Pedro generalmente es alto/inglés.

e, *Pedro generalmente sabe inglés.

(21d) y (21e) muestran que si se trata de propiedad inalienable, nacionalidad o de capacidad de una sola persona no podemos utilizar el adverbio generalmente. Sin embargo, en (20b), (20d), (20f) y (21a-c) se trata de un grupo. La perífrasis se refiere a una característica típica de los miembros pertenecientes a este grupo.

Las perífrasis verbales fasales son las construcciones con las que es posible poner énfasis en diferentes fases de una situación: en el inicio (ponerse a + infinitivo, empezar / comenzar a + infinitivo, echarse a + infinitivo), en la fase interna (seguir + gerundio, estar + gerundio, no dejar / no parar de + infinitivo) y en el término (acabar de + infinitivo, dejar de /parar de + infinitivo, tener + participio). Es necesario mencionar, aparte de estos tres tipos, las perífrasis que se refieren a una fase preparatoria como estar a punto de + infinitivo e ir a + infinitivo si se utiliza en pretérito imperfecto. Esta última perífrasis conjugada en presente se refiere a un evento del futuro. En cambio, conjugada en pretérito imperfecto puede expresar una situación que estaba a punto de ocurrir pero algo lo impidió. En el caso de los estados no es siempre posible destacar una de las fases de la situación, especialmente la fase inicial o la fase final, puesto que a veces es difícil determinar el punto inicial o el punto final de un estado. Como vamos a ver, esto 
Las restricciones en el uso de los predicados estativos en la lengua española

generalmente ocurre con los predicados estativos que expresan propiedad inalienable, nacionalidad, capacidad y estado mental o físico.

22 a, *Se puso a ser alto.

b, *Dejó / paró de ser inglés.

c, $*$ Se puso a saber español.

$\mathrm{d}, *$ Se pone a estar cansado.

El problema en el caso de (22a-d) es que los predicados estativos siempre expresan una situación estática, sin embargo, estas perífrasis requieren una situación dinámica.

En esta parte voy a analizar el uso de las perífrasis fasales con los distintos tipos de estados. Las construcciones que destacan la fase preparatoria generalmente no pueden ser utilizadas con la mayoría de los estados:

23 a, *Está a punto de ser alto /inglés.

b, *Está a punto de saber inglés.

c, *Estaba a punto de estar cansado.

d, Está a punto de residir en Madrid.

e, Estaba a punto de tener dos coches.

f, Estaba a punto de ser denominado como el Rey del fútbol.

g, *Está a punto de parecerse a su padre.

h, Está a punto de conocer su nuevo profesor.

i, *Está a punto de temer a la oscuridad.

24 a, *Iba a ser inteligente /inglés cuando me trasladé a Hungría.

b, *Iba a saber leer cuando empecé la escuela.

c, *Iba a estar cansado cuando me llamó mi jefe.

d, Iba a residir en Madrid cuando encontré trabajo en Granada.

e, Iba a tener dos coches cuando perdió su trabajo.

f, Iba a ser denominado como el Rey del fútbol cuando se le rompió la pierna.

g, *Iba a parecerse a su padre cuando empezó la escuela.

h, Iba a conocer a mi nuevo profesor cuando me puse enferma.

i, *Iba a temer a la oscuridad cuando empezó a vivir con sus abuelos.

Ambas construcciones son incompatibles con la mayoría de los estados porque estas situaciones son estables, así que no se puede destacar la fase preparatoria que avanza hacia la situación. Esto es posible solo en el caso de un evento dinámico. En caso de (23h) y (24h) el tipo de situación cambia: en estas oraciones la situación puede ser interpretada solo como una realización. (23d-e) y (24d-e) expresan situaciones que pueden ser interpretadas como periódicas y estas situaciones tienen "agente", por eso es posible utilizar las perífrasis con estos tipos de estados. (23f) y (24f) expresan el resultado de una acción.

Voy a distribuir en dos clases las perífrasis que ponen énfasis en la fase inicial de la situación. Ponerse a + infinitivo y echarse + infinitivo se refieren a un inicio repentino, mientras que este significado no aparece en el caso de comenzar a + infinitivo y empezar a 
+ infinitivo. En los siguientes ejemplos voy a presentar el uso posible de los estados con estas perífrasis.

25 a, *Se pone / se echa a ser inteligente /inglés.

b, *Se puso / se echó a saber leer.

c, $*$ Se pone / se echa a estar cansado.

d, *Se pone / echa a tener dos casas.

e, $*$ Se pone / echa a residir en Madrid.

f, *Se pone /echa a parecerse a su padre.

$\mathrm{g}, *$ Se puso a ser considerado como un príncipe.

h, Se puso / echó a conocer la ciudad.

i, *Su puso / echó a temer a las sombras.

Podemos ver que las perífrasis ponerse a + infinitivo y echarse a + infinitivo no son compatibles con ninguno de los estados, no solo porque en general requieren una situación dinámica sino por el inicio repentino que expresan. La única excepción es (25h) que, en este caso, solo puede ser interpretado como una realización.

Las dos otras perífrasis muestran diferencias:

26 a, *Comienza / empieza a ser alto /inglés.

b, Comenzó /empezó a saber leer.

c, Comienza /empieza a estar cansado.

d, *Comenzó /empezó a tener dos coches.

e, Comienza a tener canas.

f, Comenzó /empezó a residir en Madrid.

g, Comienza /empieza a parecerse a su padre.

h, Comenzó / empezó a ser denominado como el Rey del fútbol.

i, Comenzó /empezó a conocer la ciudad.

j, Comenzó /empezó a temer a las sombras.

Comenzar a + infinitivo y empezar a + infinitivo también se refieren al inicio, pero en este caso el inicio puede ser más "lento". En (26a) y (26d) podemos ver que los estados que expresan propiedades inalienables, nacionalidad o posesión no pueden aparecer con estas perífrasis tampoco. Por la estatividad de estas situaciones no es posible poner énfasis en el inicio. Sin embargo, en los demás casos pueden aparecer los estados con estas perífrasis. En (26b) y (26i) las oraciones se refieren a la adquisición del conocimiento, así que en estas frases la situación tiene que ser interpretada como una realización. Según mi opinión, en (26f) también la realización es la única interpretación posible, puesto que la oración expresa un cambio, el traslado a otra ciudad. Las situaciones de (26c), (26e), (26g), (26h) y (26j) son menos estáticas que (26b) y (26i), mejor dicho, el inicio de la situación puede componerse de distintos períodos que se refieren al comienzo de la situación.

Las perífrasis que destacan la fase final de las situaciones a veces pueden aparecer con los predicados estativos. Estas construcciones también se diferencian entre sí: acabar de + infinitivo y tener + participio requieren un desarrollo anterior, pero en el caso de 
Las restricciones en el uso de los predicados estativos en la lengua española

dejar de + infinitivo esto no es necesario. Por eso acabar de + infinitivo y tener + participio no son compatibles con la mayoría de los estados:

27 a, *Acaba de ser alto /inglés.

b, *Acaba de saber inglés.

c, ${ }^{*}$ Acaba de estar cansado.

d, *Acabé de tener dos coches.

e, *Acabé de residir en Madrid.

f, *Acabó de parecerse a su padre.

g, *Acabó de ser denominado como el Rey del fútbol.

h, Acabó de conocer la ciudad.

i, *Acabé de temer a la oscuridad.

Podemos ver que el único caso aceptable es $(27 \mathrm{~h})$ en el que la situación debe ser interpretada como una realización y no como un estado. La construcción tener + participio es incompatible con los estados no solo porque esta perífrasis se refiere al resultado de un proceso, es decir siempre requiere un desarrollo anterior, sino porque esta perífrasis generalmente se utiliza solo con verbos transitivos, sin embargo, la mayoría de los predicados de estado son intransitivos.

28 a, *Tiene sido alto /inglés.

$\mathrm{b}$, *Tiene sabido inglés.

c, *Tiene estado cansado.

d, *Tengo tenidos dos coches.

e, *Tengo residido en Madrid.

$\mathrm{f}$, *Se tiene parecido a su padre.

$\mathrm{g}$, *Tiene sido considerado como un príncipe.

$\mathrm{h}$, *Tiene conocida la ciudad.

i, *Tengo temido a la oscuridad.

En los siguientes ejemplos voy a analizar qué diferencias muestran las perífrasis dejar de + infinitivo y parar de + infinitivo.

29 a, *Dejó de ser inteligente /inglés.

b, *Dejó de saber leer ${ }^{3}$.

c, Dejó de estar cansado.

d, Dejó de tener dos coches.

e, Dejó de residir en Madrid.

f, Dejó de parecerse a su padre.

g, Dejó de ser denominado como el Rey del fútbol.

h, *Dejó de conocer la ciudad.

i, Dejó de temer a la oscuridad.

\footnotetext{
${ }^{3}$ Esta oración puede aparecer en cierto contexto: Después del accidente dejó de saber leer.
} 
A pesar de la estabilidad de los estados, (29c-g) y (29i) muestran que es posible utilizar la perífrasis dejar de + infinitivo con algunos predicados estativos. En estos casos la perífrasis expresa que la situación cesa y que la situación alcanza su final natural. Este final puede ser repentino, sin embargo, el mismo estado no puede continuar, solo es posible que vuelva a comenzar, pero en este caso se trata de una situación nueva. La diferencia entre una situación estática y una situación dinámica es que la primera cesa, mientras la segunda se interrumpe. Por eso, a una oración de evento dinámico se puede añadir el adverbio de tiempo un momento: Pedro dejó de trabajar por un momento para coger el teléfono. Sin embargo, en el caso de un estado esto no es posible: *Pedro dejó de temer a la oscuridad por un momento para entrar al sótano. En (29h), a pesar de que la oración tiene "agente", y en (29a) y (29b) no es posible expresar que la situación termina, puesto que las propiedades inalienables, la nacionalidad y el conocimiento no son situaciones delimitables, es decir no tienen límites, por eso no pueden cesar tampoco (De Miguel, 1999: 3012).

La construcción parar de + infinitivo se comporta de manera diferente:

30 a, *Paró de ser inteligente /inglés.

b, *Paró de saber leer.

c, *Paró de estar cansado.

d, *Paró de tener dos coches.

e, *Paró de residir en Madrid.

f, *Paró de parecerse a su padre.

g, *Paró de ser considerado como un príncipe.

h, *Paró de conocer la ciudad.

i, *Paró de temer a la oscuridad.

Podemos ver que esta construcción no puede ser utilizada con ninguno de los predicados estativos. Esta perífrasis solo puede expresar la interrupción de una situación que, como hemos visto más arriba, no es posible en el caso de un estado.

Ahora voy a pasar a las perífrasis que ponen énfasis en la fase interna de una situación. Seguir + gerundio, no dejar de + infinitivo y no parar de + infinitivo son sinónimas, destacan la fase interna, sin marcar el punto inicial o el punto final de la situación, y de esta manera poseen las mismas características que un estado: son estáticas y durativas. Por eso, estas construcciones pueden ser utilizadas con los predicados estativos.

31 a, Sigue siendo inteligente /inglés.

$\mathrm{b}$, Sigue sabiendo nadar.

c, Sigue estando cansado.

d, Sigue teniendo dos casas.

e, Sigue residiendo en Madrid.

f, Sigue pareciéndose a su padre.

$\mathrm{g}$, Sigue siendo considerado como un príncipe.

$\mathrm{h}$, Sigue conociendo la ciudad.

i, Sigue temiendo a la oscuridad.

Acta Hispanica 25: 67-86, 2020, ISSN 1416-7263, e-ISSN 2676-9719 | 81 
Las restricciones en el uso de los predicados estativos en la lengua española

32 a, No dejó / paró de ser inteligente /inglés.

b, No dejó / paró de saber nadar.

c, No dejó / paró de estar cansado.

d, No deja / para de tener dos casas.

e, No dejó / paró de residir en Madrid.

f, No deja /para de parecerse a su padre.

g, No deja / para de conocer la ciudad.

h, No dejó / paró de temer a la oscuridad.

La perífrasis progresiva estar + gerundio muestra diferencias:

33 a, *Está siendo inteligente /inglés.

b, *Está sabiendo inglés.

c, *Está estando cansado.

d, *Está teniendo dos coches.

e, *Está residiendo en Madrid.

f, *Está pareciéndose a su padre.

$\mathrm{g}$, Está siendo considerado como un príncipe.

h, Está conociendo la ciudad.

i, *Está temiendo a la oscuridad.

(33a-i) muestra que la perífrasis progresiva estar + gerundio no puede ser utilizada con estos estados porque sería contradictorio destacar el progreso de una situación estable que no manifiesta avance o cambio (De Miguel, 1999: 3013). La única excepción es (33h) que se interpreta en esta construcción como una realización. Sin embargo, si destacamos el carácter transitorio de la situación o los estados aparecen en un contexto actual, algunos predicados estativos también pueden aparecer en esta construcción (Yllera, 1999: 3412):

34 a, *Actualmente está siendo inglés / inteligente.

$\mathrm{b}, *$ Actualmente está sabiendo inglés.

c, *Actualmente está estando cansado.

d, Actualmente está teniendo dos coches.

e, Durante el semestre está residiendo en Madrid.

f, Con este comportamiento está pareciéndose a su padre.

g, Últimamente, Pedro está siendo denominado como el Rey del fútbol.

h, Últimamente, mi hijo está temiendo a la oscuridad.

En (34a-c) podemos ver que estos estados no pueden aparecer en la perífrasis progresiva ni siquiera si cambiamos el contexto a un contexto actual. Sin embargo, en (34d-h) la actualización de la situación, destacando el carácter transitorio del estado, hace posible el uso de la perífrasis. 


\section{Conclusión}

En este estudio he presentado algunas restricciones referentes al uso de los predicados estativos en la lengua española. Hemos visto que algunas propiedades típicas de los estados no siempre se cumplen. La (in)compatibilidad con el modo imperativo, con el imperativo negativo, con construcciones de petición, con los adverbios de modo depende de la agentividad, puesto que estas construcciones requieren que la oración tenga agente. Según la afirmación de Smith, los estados, como son estáticos, no pueden tener agente. Sin embargo, en este estudio he demostrado que algunos predicados estativos también pueden tener agente, o al menos un sujeto que, hasta cierto punto, es capaz de controlar la situación.

En el caso de las perífrasis verbales fasales no es la agentividad lo que determina el uso de ciertas perífrasis con los predicados de estado, sino que la compatibilidad depende de distintos factores. Por ejemplo, la posibilidad de que el estado cese, da como resultado la compatibilidad del predicado estativo con las perífrasis dejar de + infinitivo. Si se puede interpretar el estado como periódico, es posible poner énfasis en su inicio, así que podemos utilizar el predicado con las perífrasis que destacan la fase preparatoria del evento y con las perífrasis comenzar /empezar a +infinitivo. En el caso de seguir + gerundio y no dejar / parar de + infinitivo las propiedades semejantes, como la estatividad y la duratividad, hacen posible utilizar las construcciones con los predicados estativos. Hemos visto que la perífrasis progresiva solo es compatible con algunos de los estados si destacamos el carácter transitorio o la actualidad de la situación. Las perífrasis parar de + infinitivo, acabar de + infinitivo y tener + participio son incompatibles con todos los predicados estativos. En las siguientes tablas voy a resumir los tipos de los predicados estativos y las construcciones analizadas. En la primera aparecen las construcciones cuyo uso depende de la agentividad y en la segunda presento el resumen del uso de las perífrasis verbales fasales ${ }^{4}$.

\begin{tabular}{|l|l|l|l|l|l|l|}
\hline & \multicolumn{6}{|l|}{ Construcciones analizadas } \\
\hline Tipo de estado & $\begin{array}{l}\text { Modo } \\
\text { imperativo }\end{array}$ & $\begin{array}{l}\text { Imperativo } \\
\text { negativo }\end{array}$ & $\begin{array}{l}\text { Verbos } \\
\text { de } \\
\text { petición }\end{array}$ & $\begin{array}{l}\text { Adverbios } \\
\text { de modo }\end{array}$ & $\begin{array}{l}\text { Levar }+ \\
\text { gerundio }\end{array}$ & $\begin{array}{l}\text { Soler }+ \\
\text { infinitivo }\end{array}$ \\
\hline $\begin{array}{l}\text { Propiedad } \\
\text { inalienable }\end{array}$ & - & - & - & - & - & - \\
\hline Nacionalidad & - & - & - & - & - & - \\
\hline $\begin{array}{l}\text { Estado físico o } \\
\text { mental no } \\
\text { permanente }\end{array}$ & + & + & + & - & + & + \\
\hline Capacidad & - & - & - & - & - & - \\
\hline
\end{tabular}

${ }^{4}$ En estas tablas no aparecen los usos de contexto específico, como la actualización de la situación en caso de estar + gerundio o el contexto general en caso de soler + infinitivo.

${ }^{5}$ No aparece el caso cuando el adverbio modifica el "agente". 
Las restricciones en el uso de los predicados estativos en la lengua española

\begin{tabular}{|c|c|c|c|c|c|c|}
\hline Conocimiento & + & + & + & - & + & + \\
\hline $\begin{array}{l}\text { Permanencia en un } \\
\text { estado o situación }\end{array}$ & + & + & + & - & + & + \\
\hline Posesión & + & + & + & - & + & + \\
\hline Verbos sentiendi & + & + & + & - & + & + \\
\hline $\begin{array}{l}\text { Verbos } \\
\text { pseudoatributivos }\end{array}$ & - & - & - & - & - & - \\
\hline $\begin{array}{l}\text { Verbos } \\
\text { pseudoatributivos } \\
\text { de tipo ser }+ \\
\text { participio }+ \text { como }\end{array}$ & - & - & - & - & + & + \\
\hline
\end{tabular}

\begin{tabular}{|l|l|l|l|l|l|l|l|l|l|}
\hline & $\begin{array}{l}\text { Perífrasis de } \\
\text { fase } \\
\text { preparatoria }\end{array}$ & $\begin{array}{l}\text { Ponerse } \\
\text { lecharse } \\
a+\text { inf. }\end{array}$ & $\begin{array}{l}\text { Comenzar } \\
\text { lempezar } \\
\text { a inf. }\end{array}$ & $\begin{array}{l}\text { Perífrasis } \\
\text { de fase } \\
\text { interna }\end{array}$ & $\begin{array}{l}\text { Estar } \\
+ \\
\text { ger. }\end{array}$ & $\begin{array}{l}\text { Dejar } \\
\text { de }+ \\
\text { inf. }\end{array}$ & $\begin{array}{l}\text { Acabar } \\
\text { de }+ \\
\text { inf. }\end{array}$ & $\begin{array}{l}\text { Tener } \\
+ \\
\text { part. }\end{array}$ & $\begin{array}{l}\text { Parar } \\
\text { de }+ \\
\text { inf. }\end{array}$ \\
\hline $\begin{array}{l}\text { Propiedad } \\
\text { inalienable }\end{array}$ & - & - & - & + & - & - & - & - & - \\
\hline Nacionalidad & - & - & - & + & - & - & - & - & - \\
\hline $\begin{array}{l}\text { Estado físico o } \\
\text { mental no } \\
\text { permanente }\end{array}$ & - & - & + & + & - & + & - & - & - \\
\hline Capacidad & - & - & + & + & - & - & - & - & - \\
\hline Conocimiento & - & - & + & + & - & + & - & - & - \\
\hline $\begin{array}{l}\text { Permanencia en } \\
\text { un estado o } \\
\text { situación }\end{array}$ & + & - & + & + & - & + & - & - & - \\
\hline Posesión & + & - & + & + & - & + & - & - & - \\
\hline Verbos sentiendi & - & - & + & + & - & + & - & - & - \\
\hline $\begin{array}{l}\text { Verbos } \\
\text { pseudoatributivos }\end{array}$ & - & - & + & + & - & + & - & - & - \\
\hline $\begin{array}{l}\text { Verbos } \\
\text { pseudoatributivos } \\
\text { de tipo ser + } \\
\text { participio + como }\end{array}$ & + & - & + & + & - & + & - & - & - \\
\hline
\end{tabular}

La tabla muestra que solo los adverbios de modo, referentes al predicado, y la perífrasis estar + gerundio no pueden ser utilizados con ninguno de los estados. Podemos ver también que los predicados estativos que se refieren a propiedad inalienable, a nacionalidad, a capacidad y los verbos pseudoatributivos no pueden ser utilizados con el modo imperativo (negativo), con las construcciones de petición y con las perífrasis aspectuales. Estos predicados de estado, generalmente, expresan una situación que no puede ser modificada y no tiene agente, por eso no es posible utilizarlos en construcciones que requieren agente. Como, normalmente, no pueden ser modificados, no tiene sentido destacar el carácter inclusivo o iterativo de estos estados. Los demás predicados estativos que pueden ser controlados por un "agente" pueden aparecer con 
el modo imperativo (negativo), con los verbos de petición. Así que se puede afirmar que en el caso de estas construcciones la agentividad determina la compatibilidad con los estados. Los verbos pseudoatributivos de tipo ser + participio como muestran diferencias, puesto que estos estados pueden aparecer en las construcciones aspectuales. Esto se debe al carácter no permanente de estos estados. En el caso de las perífrasis aspectuales, el carácter temporal de la situación hace posible el uso de llevar + gerundio con los estados no permanentes y la posibilidad de interpretar la situación como un estado general o como una costumbre da como resultado la compatibilidad de soler + infinitivo con los mismos predicados estativos.

Como ya he mencionado más arriba, en el caso de las perífrasis fasales, otras propiedades determinan la compatibilidad con los estados. Las dos construcciones analizadas que pueden aparecer con todos los estados son las perífrasis que destacan la fase interna de la situación. En el caso de las perífrasis que destacan la fase preparatoria, la agentividad y el carácter periódico de la situación hacen posible el uso de estas construcciones con los estados que expresan permanencia en un estado o posesión y con los verbos pseudoatributivos de tipo ser + participio + como. La compatibilidad de algunos estados con las perífrasis comenzar/empezar a +infinitivo también se debe al carácter periódico de estos estados. Si es posible que la situación cese, es posible el uso de la perífrasis dejar de + infinitivo. Las demás construcciones no pueden aparecer con ninguno de los estados porque expresan el inicio repentino de la situación (ponerse lecharse a + infinitivo) o requieren un desarrollo anterior (acabar de + infinitivo, tener + participio) o expresan una interrupción (parar de + infinitivo).

Como conclusión, quisiera afirmar que los predicados estativos muestran muchas diferencias entre sí, la posibilidad de que el sujeto puede controlar la situación es una característica que distribuye en dos partes los predicados estativos. Otras diferencias importantes son por ejemplo la existencia de un final posible, la posibilidad de interpretar la situación como periódica etc. Según mi opinión, estas características pueden servir de base de una clasificación más detallada de los predicados de estado.

\section{Referencias bibliográficas}

De Miguel, Elena (1999). El aspecto léxico. En: Bosque, Ignacio - Demonte, Violeta (eds.) Gramática descriptiva de la lengua española 2- Las construcciones sintácticas fundamentales, relaciones temporales, aspectuales y modales. Madrid: Espasa Calpe. 2979-3060.

Katz, Graham (2003). Event arguments, adverb selection, and the Stative Adverb Gap. En: Ewald Lang - Claudia Maienborn - Cathrine Fabricius Hansen (eds.) Modifying Adjuncts (Interface Explorations 4). Berlin: De Gruyter Mouton. 455-474.

Kovacci, Ofelia (1999). El adverbio. En: Bosque, Ignacio - Demonte, Violeta (eds.) Gramática descriptiva de la lengua española 1 - Sintaxis básica de las clases de palabras. Madrid: Espasa Calpe. 705-786. 
Las restricciones en el uso de los predicados estativos en la lengua española

Laca, Brenda (2005). Tiempo aspecto y la interpretación de los verbos modales en español. Lingüistica ALFAL, 17. 9-44.

Ramírez Gelbes, Silvia (2013). Los predicados estativos y la evidencialidad: Un análisis desde la Teoría de los Bloques Semánticos. Revista de Lingüistica Teórica y Aplicada Concepción (Chile), 51 (1), I Sem. 101-125.

Smith, Carlota S. (1997). The parameter of aspect (second edition). Dodrecht: Kluwer.

Yllera, Alicia (1999). Las perífrasis verbales de gerundio y participio. En: Bosque, Ignacio - Demonte, Violeta (eds.) Gramática descriptiva de la lengua española 2- Las construcciones sintácticas fundamentales, relaciones temporales, aspectuales y modales. Madrid: Espasa Calpe. 3393-3441. 